\title{
The Effect of Whiteness and Attempts to Preserve It on Political Division in the United States
}

\author{
Therin Showalter \\ Faculty Mentor: Michael Leonard, The Media School, Indiana University Bloomington
}

\begin{abstract}
Beginning in the early 1990s, the American public has become increasingly politically polarized. As party affiliations have become more rigid, a racial trend has emerged in which white voters are much less likely than black voters to identify as liberal or align with the Democratic Party. Using voting data from the 2016 presidential election, this study correlates the prevalence of whiteness in certain counties with those counties' support for Democratic presidential candidate Hillary Clinton. This paper first details the increasing polarization over the past decades and the dramatic shift of white voters away from liberalism. It then analyzes the political affiliations of other identity groups (such as women, millennials, and college graduates) that are majority liberal and demonstrates that, when restricted to their white members, those groups all lean conservative.

The research results find a significant correlation between concentrated whiteness and a rejection of Hillary Clinton. The correlation on a national level is weaker, however, than the correlation of counties when separated regionally, suggesting that the relationship between whiteness and anti-liberalism depends heavily on a county's degree of whiteness (or anti-liberalism) in its geographical context. While it is impossible to determine whether the race of white voters consciously motivates their voting behavior, the results suggest that American democracy is informed, in some way, by the racial identities of its participants.
\end{abstract}

KEYWORDS: voting behavior, 2016 election, racial politics, whiteness

\section{INTRODUCTION}

$\mathrm{O}$ ver the last three decades, political divisions in the United States have widened by nearly every metric and to a worrisome degree. Although riots, demonstrations, and culture wars are common in the turbulent and storied history of this nation, the increasing depth and intensity of these divisions have cultivated a troubling level of animosity between fellow Americans, driven by the partisanship pervading their political preferences, social lives, and, most importantly, their sense of personal identity.

A 2017 survey by Pew Research Center, titled "The Partisan Divide on Political Values Grows Even Wider," found that 65 percent of Democrats and 55 percent of Republicans have "just a few" or no friends in the opposing party. Unsurprisingly, that same study found a dramatic increase in each party's antipathy toward the other. Since 1994, the percent of Democrats and Republicans who hold a "very unfavorable" view of the opposing party has risen from 16 and 17 percent to 44 and 45 percent, respectively, nearly tripling over a 23 -year period.

Pew (2017) also reported that the group of people who hold a well-balanced blend of liberal and conservative beliefs has almost entirely disappeared. In 1994, 36 percent of Republicans held more liberal views than the average Democrat, and 30 percent of Democrats held more conservative views than the average Republican. Today, those figures have plummeted to five and three percent, respectively. These findings indicate that each of the major political parties and its respective ideological affiliations is now completely opposed to the other, so much so that most voters/ members are no longer friends with anyone from the other party and few people share even a semblance of similar views with the other side.

This hyper-partisanship in social circles and personal identities translates plainly into geographic clustering based on voting behavior. A 2017 analysis by David Wasserman of FiveThirtyEight found that of the nation's 3,113 counties (or county equivalents), only 303 were decided by single-digit percentage margins in the 2016 presidential election. In 1992, conversely, 1,096 counties fell within that category. Meanwhile, the number of counties decided by a margin of 50 percent or greater exploded from 93 in 1992 to 1,196 in 2016. This means Americans are increasingly likely to find themselves living among people who share their political views with few, if any, dissenters. Such constraints could result in echo chambers that make it difficult for people to gain personal exposure to differing opinions and might restrict the exchange of information and ideas that are often regarded as key to a healthy, functioning democracy.

Additionally, on a national scale, the margins by which presidents have won the Electoral College have tightened sharply since the election of Bill Clinton in 1992, which coincides with the trends detected by the data from Pew (2017). Between 1928 and 1988, 75 percent of presidential elections were won with at least 426 electoral votes, representing more than 80 percent of the College. In fact, during that same period, a presidential candidate surpassed the 90 percent threshold on five occasions, indicating a flexibility in voters to agree with more than just their neighbors. Today, when nearly a third of all counties are won by a 50 percent margin or greater, capturing even 380 electoral votes appears extremely unlikely. Combined with geographical echo chambers, these data suggest that elections and public discourse in America are becoming hyper-polarized with little room for change in an individual's party affiliation. Voters crossing party lines were more common and fluid several decades ago, but now those identities are more rigid.

This set of data clearly defines the rift that has been sown between voters. America may be a divided nation, but understanding the causes of this hyper-partisanship requires more than simply acknowledging its existence in its various iterations. This study seeks to explain these divisions by researching the effect of whiteness on Americans' sociopolitical identities and voting behavior. Looking at these issues from a racial perspective allows for the identification of one common denominator among a variety of issues, controversies, and policy debates. Although Americans seem divided on virtually every major political topic, this study focuses on one potential cause and motivation for our political strife by testing the relationship 
between whiteness and presidential voting patterns. In order to do so, the degree of whiteness in certain counties was measured against those counties' support for Democratic candidate Hillary Clinton in the most recent presidential election.

\section{DEMOGRAPHIC MISCONCEPTIONS}

Several statistics describing the political affiliations of certain demographic groups paint a misleading picture. Information on extremely broad classifications of people, such as women, millennials, and those with a college degree, seems to suggest that these groups are uniformly more liberal than their counterparts. Indeed, when Pew Research Center published its "Deep Dive into Party Affiliation" in 2015, one of its subheadings read, "Gender Gap in Party Identification Persists." The claim was supported by data that said women lean Democratic by a margin of 12 percent, whereas men only lean that way by a margin of 1 percent. Similar claims are made of millennials, who Pew (2015) reported lean to the political left by a margin of 16 percent. College graduates lean left by a margin of 12 percent.

These statistics tend to suggest that subsequent generations become more progressive, collegiate education leads to liberalism, and women perceive some ill will toward their interests in the Republican agenda, but none of these trends can eclipse the overwhelming conservatism of white Americans. Of all the demographic variables attributed to one's political affiliation, whiteness most strongly predicts conservative values over any other factor.

While millennials may lean left by a 16 percent margin, white millennials lean right by a margin of 2 percent. White women voted for Donald Trump in 2016 by a margin of 9 percent, as did white college-educated voters by a margin of 3 percent. Writing for The Atlantic, Ta-Nehisi Coates (2017) cites exit-polling data to further support the power whiteness played in the 2016 election across other demographics: "According to Edison Research, Trump won whites making less than $\$ 50,000$ by 20 points, whites making $\$ 50,000$ to $\$ 99,999$ by 28 points, and whites making $\$ 100,000$ or more by 14 points. Trump won whites in Midwestern Illinois (+11), whites in mid-Atlantic New Jersey $(+12)$, and whites in the Sun Belt's New Mexico (+5)." Whiteness, he concludes, supersedes all other classifications when predicting voting behavior.

Even cultural preferences that fuel political division, such as gun ownership, may also correlate with whiteness. The New York Times, for example, published an article in October 2017 with the headline "Nothing Divides Voters Like Owning a Gun." It displayed two electoral maps. One showed the results of the 2016 election had only voters who live in households with guns been allowed to vote. The other showed the results decided by voters without guns. As expected, among gun owners, every state except New Hampshire voted for Trump. Among those without guns, every state except West Virginia voted for Hillary Clinton. On its face, this may appear to attest to a sharp cultural or policy divide, but Pew Research Center noted in a June 2017 study that whites are 50 percent more likely than blacks to be gun owners and more than twice as likely compared to Hispanics.

Overall, it has been shown that since the early nineties, Americans have become more partisan, more antipathetic toward those of the opposing party, and more adherent to a strict set of liberal or conservative beliefs, but something else has happened since then. The share of registered voters who are non-white has nearly doubled, rising from 16 percent to 30 percent, and nonwhites tend to be extremely left-leaning (blacks by a margin of 69 percent and Hispanics by a margin of 30), according to a 2016 study by Pew.
History has clearly shown that racially charged attitudes had been prevalent on both sides of the political aisle prior to the early nineties, when political discussion was dominated by white voices. According to Pew (2017), in 1994, 53 percent of Democrats and 66 percent of Republicans believed that "Blacks who can't get ahead in this country are mostly responsible for their own condition.” Today, the percentage of Democrats who still hold that belief has dropped to 28 percent, while the Republican figure has risen to 75 percent. This means political affiliation hasn't always been an indicator of racial prejudices, nor has whiteness been such a consistently strong indicator of conservatism.

What these data demonstrate is that America's deep-seated political divisions began with the attachment of a racial identity to each political party. As non-whites became more visible, more vocal, and more numerous, their affiliation with liberalism functioned as a catalyst for a "white-lash" into conservatism, similar to the phenomenon of "white flight." Now, instead of moving themselves physically when black bodies invaded white neighborhoods, they have moved themselves ideologically as black (and other non-white) minds permeate their ideological territory.

While this correlation has not held true for all white people (40 percent of them still lean to the left (Pew 2015), the data presented thus far, as well as research on race and immigration in the 2016 election, prove that the essence of whiteness-and the need to preserve it-are strong motivators for voting against the party with which minority voters are most often aligned.

\section{LITERATURE REVIEW}

Research in this field has been insightful, but it has also been limited in its scope. In an article for The New York Times titled "How Immigration Foiled Hillary,” Pulitzer Prize nominee Thomas Edsall (2017) describes how increased immigration rates in counties that initially had a low level of diversity motivated its white residents who had previously voted for Barack Obama to vote for Donald Trump.

To measure this phenomenon, a diversity index was used to estimate the probability that any two residents of a certain county chosen at random would be of different races. A lower diversity score, on a 1-100 scale, meant that most of the residents are of the same race, whereas a higher score indicated higher racial diversity. The United States, as a nation, has a diversity score of 63, which has increased by 28.6 percent over the last 15 years. Edsall notes that counties where the diversity score exploded in that same time period supported Trump by unprecedented margins. In particular, this occurred in counties in the crucial swing states of Wisconsin, Michigan, and Pennsylvania.

For example, Luzerne County, Pennsylvania, supported Barack Obama in 2012 by a margin of 4.8 percent, but after its diversity score increased from 8 to 36.6 (a 360 percent increase over the 15 years between 2000 and 2015), it supported Donald Trump in 2016 by 19.3 percent. In Wisconsin, the diversity score for Adams County increased by 204 percent, going from 7 to 21.3. It supported Obama in 2012 by a margin of 8.8 percent but turned to Trump in 2016 by a margin of 21.9 points-a shift of more than 30 points. Finally, Macomb County, Michigan, backed Obama in 2012 by 4 points, but supported Trump in 2016 by 11.6 points after its diversity score increased 116 percent, going from 16 to 34.5 . In these instances, the proliferation of whiteness did not motivate these residents to reject liberalism until the sanctity of their whiteness was threatened by the existence of non-white immigrants.

This behavior is confirmed by research from Benjamin Newman in a 2013 study published by the American Journal of Political Science. He writes, "Growth in local Hispanic populations triggers 
threat and opposition to immigration among whites residing in contexts with few initial Hispanics, but reduces threat and opposition to immigration among whites residing in contexts with large preexisting Hispanic populations." As it pertains to this research, Newman seems to indicate that some white-dominated counties may not reject liberalism until they experience an influx of non-white people, but the relationship between whiteness and anti-liberalism holds true either way.

Edsall used individual counties as anecdotal examples to support an opinion column, while Newman's research exclusively focused on counties that experienced growth in their Hispanic population. What this research hopes to fulfill is a comprehensive examination of the United States as a whole and, specifically, how the prevalence of white people (rather than any one minority ethnic group) relates to the voting behavior of that county.

\section{RESEARCH ON WHITENESS AND VOTING}

Based on the data presented in the preceding sections of this paper, this study predicts:

There will be a negative correlation between the share of white people in United States counties and those counties' support for Hillary Clinton in the 2016 presidential election.

\section{Methodology}

A random sample of 150 counties was selected, representing approximately 2.5 percent of all counties. Counties were listed in alphabetical order within their respective states, which were also listed alphabetically, and each county was then numbered from 1 to 3,113 . A computer randomly generated a set of 150 numbers from among those values and each of the numerically assigned counties corresponding to one of the randomly generated numbers was selected.

Not all states were included in the sample. The randomly generated numbers did not select any county from the following states: Alaska, Connecticut, Delaware, Hawaii, Maine, Maryland, Massachusetts, New Hampshire, Utah, Vermont, and Wyoming. Overall, however, the counties still represented a wide range of whiteness levels and support for Clinton. For whiteness, the minimum and maximum percentages were 6.1 and 98.2, respectively, with a mean of 78.3. For Clinton support, the minimum and maximum percentages were 6.3 and 82.6, respectively, with a mean of 32.6. 39 states were represented in the sample.

Utilizing data from the Census Bureau, based on the 2010 census, the racial makeup of each selected county-specifically, the percent non-Hispanic white-was recorded. Finally, the share of the vote Hillary Clinton won in that county in the 2016 election was also recorded. Because this paper posits that the identification of whiteness with conservatism was reactionary to the identification of non-whiteness with liberalism, it was necessary to test the resistance of whiteness to the Democratic Party, instead of its attraction to the Republican Party.

\section{Results}

A statistically significant correlation was found between higher whiteness and lower support for Hillary Clinton in the selected counties. Therefore, the initial hypothesis that a negative correlation would be observed between the share of white people in United States counties and those counties' support for Hillary Clinton in the 2016 presidential election was supported $(\mathrm{r}(148)=-0.533, \mathrm{p}<0.001)$. The table lists the complete results.

In addition to analyzing all counties as a whole, counties were analyzed in groups according to their location in either a Democratic (blue) or Republican (red) state. The correlation strengthened significantly among counties within Democratic states $(r(35)=-$ $0.821, \mathrm{p}<0.001$ ), likely due to the heightened variance between urban and rural counties in those states. Los Angeles County, California, for example, is only 27 percent white and 71 percent of voters chose Clinton, whereas the residents of Amador County, California, are nearly 80 percent white and only 34 percent voted for Clinton. In this case, a substantial increase in whiteness correlated with a moderate decrease in Clinton support.

A similar trend was observed in red states but often on a more condensed scale. In Calhoun County, West Virginia, where 98 percent of residents are white, only 18 percent voted for Clinton. To the southwest, in Cabell County, where 91 percent are white, support for Clinton increased to 35 percent. In this state, where the most diverse county is still 80 percent white, a slight decrease in whiteness correlated to a fairly sharp increase in Clinton support. However, to include these data points in the same set, from both Amador County and Cabell County, where the same percent of the electorate voted for Clinton despite differing levels of whiteness, negates the idea of a perfect correlation, which should be expected, given the varied sociopolitical cultures of each area. Thus, the national correlation will appear to be much weaker if each county is not contextualized geographically.

The most extreme example of this occurrence was the state of Texas. The demographics of this state defy the national averages for every piece of demographic data used in this study. Its racial makeup is only 57 percent white, which is lower than the national average, but instead of being more pro-Clinton, as the correlation suggests, the opposite is true. This is because the state's non-white voters chose Clinton at a rate of 66 percent, compared to the national average of 74 percent, according to exit polling by CNN. The data points from Texas consequently weaken the nationwide correlation because counties that are between 50-70 percent white still overwhelmingly rejected Clinton.

Taylor County, Texas, for instance, is 67 percent white, but only 22 percent of its voters selected Clinton. For comparison, Washington

Table 1.

Whiteness vs. Clinton Support

\begin{tabular}{|c|c|c|c|c|c|c|c|c|}
\hline & \multicolumn{2}{|c|}{ Percent White } & \multicolumn{2}{|c|}{ Percent Clinton } & \multirow{2}{*}{$\frac{\text { Correlation }}{\mathbf{r}}$} & \multicolumn{3}{|c|}{ Significance Test } \\
\hline & Mean & St. Dev. & Mean & St. Dev. & & t-stat & DoF & p-value \\
\hline All Counties & 78.31 & 19.11 & 32.61 & 15.13 & -0.533 & -7.66 & 148 & $<0.001$ \\
\hline Counties in Blue States & 80.12 & 16.58 & 41.1 & 13.67 & -0.821 & -8.5 & 35 & $<0.001$ \\
\hline Counties in Red States & 77.71 & 19.9 & 29.83 & 14.59 & -0.523 & -6.47 & 111 & $<0.001$ \\
\hline Excluding Texas & 80.62 & 17.41 & 33.77 & 14.66 & -0.66 & -10.13 & 133 & $<0.001$ \\
\hline Only Texas & 57.5 & 21.66 & 22.11 & 15.73 & -0.842 & -5.64 & 13 & $<0.001$ \\
\hline
\end{tabular}


County, Oregon, is 70 percent white and voted for Clinton at a rate of 59 percent. Similarly, Kleberg County, Texas, is 27 percent white and Clinton barely eked out a win with 49 percent of the vote. When the 150 counties from the sample are analyzed without the 15 counties from Texas, the Pearson correlation coefficient strengthens from $\mathrm{r}=$ -0.533 to $r=-0.66$. Additionally, when the counties from Texas are analyzed on their own, their correlation coefficient rises sharply to $\mathrm{r}=$ -0.842. Therefore, a stronger correlation should be expected relative to geography rather than a perfect correlation of the entire sample.

The relationship between increased whiteness and decreased support for Clinton in Texas, for instance, is one of the strongest correlations observed in this study. Unsurprisingly, CNN's exit polling indicated that whites in Texas only voted for Clinton at a rate of 26 percent (much lower than the national average of 37 percent). Although including the data points from Texas weakens the national correlation, when set apart, the motivating power of whiteness to vote against Clinton can be plainly seen. This example demonstrates that the geographic context of these counties has an equally important relationship with the data being tested for correlation as the variables themselves.

\section{DISCUSSION}

Given the multitude of factors that contribute to an individual's voting preference and party affiliation, it seems telling that such a strong correlation was found between whiteness and the rejection of Hillary Clinton and, by extension, the Democratic Party. In an ideal democracy, voting should be a matter of unselfish public policy expressed through intellectual disagreements concerning that policy. It would be expected, then, that how whites vote would not differ from the overall population since race doesn't affect unself-interested intelligence. These results, however, demonstrate that American political discourse is informed, at least in part, by "identity politics," in which one votes in the interests of one's own groups. The free flow of information and ideas plays a diminished role in American democracy in light of voters' tendency to reject a certain belief system based on their race. Voters should thus be obliged to consider how their race might be subconsciously influencing their voting behavior and what that means for the health of American democracy.

As mentioned in the methodology, this research tested the resistance of whiteness to the Democratic Party, instead of its attraction to the Republican Party. This was particularly essential for the 2016 election, when third-party votes increased dramatically (Devine \& Kopko 2016) and the two major-party candidates were the most unpopular in modern political history (Collins 2016). Had the voter share Donald Trump captured been recorded instead, white voters who voted for a third party (but traditionally lean to the right) would have been overlooked in this study.

Admittedly, there is a relationship between people of color and liberalism that this study overlooks. Given that Hillary Clinton won the vote among non-whites by a margin of 53 points in 2016 (CNN 2016) and that people of color have identified as overwhelmingly liberal as far back as the Silent Generation (Pew Research Center 2015), there surely exists a reason for this association (which some might suggest is stronger than the association of whiteness to conservatism) that this paper does not discuss. However, it is precisely the fact that people of color have voted the same way for decades, whereas white people have not, that makes the study of whiteness more relevant.

In addition to expanding the research to include people of color and their voting behaviors, a future study with the resources to analyze all of the nation's 3,113 counties would likely benefit from grouping counties by region. This method would allow researchers to control for the regions' inherent political leanings, stemming from tradition, as well as for the existing degree of whiteness in each region, which would prevent the data from painting a misleading picture when counties are removed from their geographic context. The U.S. Census Bureau, as an example of one method, distinguishes between 9 "divisions" in the United States: New England, Middle Atlantic, East North Central, West North Central, South Atlantic, East South Central, West South Central, Mountain, and Pacific (2015). Statistically strong correlations would likely be observed were the counties categorized this way, instead of together in one large, national pool. Nevertheless, the data recorded and tested here still suggests that the prevalence of whiteness pushes voters away from Democratic candidates.

Prior to 2000, there was hardly any notion of a "red wall" or a "blue wall" when describing the states as they pertained to the Electoral College. In 1964, only 6 states voted for the Republican candidate, but by 1972, a mere 8 years later, only 1 state and Washington, D.C., had voted for the Democratic candidate. The entire nation, comprised almost exclusively of white voters, flipped political preferences in the most extreme fashion, which would be nearly impossible to replicate today. As noted earlier, the majority white electorate had held a mix of liberal and conservative views, had not thought so poorly of those across the political aisle, and had been able to move freely across that aisle until around 1992. This is why asking the question "What changed about whiteness?" is more meaningful than asking "What about non-whiteness?"

\section{Limitations of Research}

Human beings are intricate and complicated creatures. Voting, in particular, is one of our most profound and deeply complex practices. It should be expected, then, that attempting to quantify and calculate these kinds of decisions has its limitations, especially concerning whiteness and voting. It is quite unlikely that race plays a conscious role for most white voters when making their decisions. Most, in all likelihood, are not overtly racist. In fact, many of the voters responsible for Trump's presidential victory (those in Michigan, Wisconsin, and Pennsylvania) previously voted for Barack Obama. However, as Newman's (2013) research showed, white voters, when perceiving increased immigration as a threat to the purity of their white communities, will vote against the political party associated with people of color. Because this may largely be a subconscious reaction, white voters will not identify themselves as racist or as acting in a racially biased manner, especially those who also voted for the first black president of the United States. Thus, being able to prove voters acted a certain way because of their race presents a particularly difficult challenge.

As for the research conducted here, several logistical concerns render the results limited in scope. Chief among them, the racial makeup of a county's residents does not necessarily equate to the racial makeup of who voted. It could easily be the case, especially in counties with large immigrant communities who may be ineligible to vote, that the share of white voters was greater than the share of white residents. Being unable to locate data for the racial makeup of 2016 voters at the county level means the results of some counties may be misrepresented.

Another limitation in this study is that every county is treated equally in the data set, despite wildly differing population sizes. This means unusual voting behavior or, more likely, unexpected turnout rates, by a handful of voters in small counties could far too easily produce outliers in the data set where they would not have otherwise been observed had the same anomaly taken place in the 
heavily-populated Cook County, Illinois, for instance. When testing for correlation, too many outliers from smaller counties can seriously weaken the results despite a strong pattern in the remaining larger counties. This study, in its current form, does not assign a weighted value to the counties based on population size.

Similarly, the relatively small sample size of this study, 150 counties, could result in inaccuracies if a few of the randomly selected counties happen to be anomalies when compared to all 3,113 counties. This becomes even more concerning when the data is divided between red and blue states and when the 15 counties from Texas are analyzed and tallied as an exclusive group. For the highest degree of accuracy and certainty, every county in the United States should be tabulated. Additionally, since this paper posits that the attachment of whiteness to conservatism happened over time, it would be beneficial to conduct the study not only for the 2016 election, but previous elections, as well. Measuring the existence of this correlation across elections would better test this hypothesis.

\section{CONCLUSION}

Because of the size of our nation and the diversity within it, the correlation between whiteness and support for Clinton on a national scale, while still relevant and insightful, becomes stronger when counties are divided into geographic regions and recalculated. An increase in whiteness among counties does correlate to a decrease in support for Hillary Clinton, but it does so on a different scale depending on the sociopolitical makeup and history of these counties' regions in such a way that grouping counties together nationally weakens the correlation.

Whiteness, even among liberal states and geographic areas, does have a relationship with rejecting the Democratic candidate, which means whiteness motivates voters, to some degree, on both sides of the political aisle. Although this study was not able to conduct research on previous election cycles, based on the surveys and polls presented earlier, it seems likely that such a relationship did not exist prior to 1992, when people of color made up less than 16 percent of the electorate and Republicans and Democrats were not nearly as polarized as they are today (Pew Research Center 2016).

The implications of this study are clear. The political division in the United States is not due to disrespect for opposing beliefs or a loss of decency in public debates, as some in the mainstream media might suggest. The attachment of white identity to a political ideology and the passionate defense of whiteness through cultural demands and public policy initiatives should not be viewed as a problem of respect, decency, or courtesy. It is a problem of racial tolerance.

This research makes clear that when the depth and intensity of our division is discussed, it should be done with a racial perspective at the forefront. To do otherwise would be to disguise the problem and ignore the evidence. That 74 percent of non-white voters supported Hillary Clinton while only 37 percent of whites did the same summarizes the challenge this nation faces in bringing its citizens together-a challenge that has sown strife into this nation's collective consciousness since its inception and one of which this nation has not yet seemed to rid itself.

\section{AUTHOR INFORMATION}

All correspondence should be sent to the first author:

therinshowalter@gmail.com

\section{REFERENCES}

CNN. (2016, November 23). Exit polls. Retrieved from http:// www.cnn.com/election/results/exit-polls
Coates, T. (2017, October). The first white president. The Atlantic, 320(3), Retrieved from https://www.theatlantic. com/magazine/archive/2017/10/the-first-white-president-tanehisi-coates/537909/

Cohn, N., \& Quealy, K. (2017, October 5). Nothing divides voters like owning a gun. The New York Times, Retrieved from https://www.nytimes.com/interactive/2017/10/05/upshot/ gun-ownership-partisan-divide.html?_r=0

Collins, E. (2016, August 31). Poll: Clinton, Trump most unfavorable candidates ever. USA Today, Retrieved from https://www.usatoday.com/story/news/politics/ onpolitics/2016/08/31/poll-clinton-trump-most-unfavorablecandidates-ever/89644296/

Devine, C., \& Kopko, K. (2016, November 15). 5 things you need to know about how third-party candidates did in 2016. The Washington Post, Retrieved from https://www. washingtonpost.com/news/monkey-cage/wp/2016/11/15/5things-you-need-to-know-about-how-third-party-candidatesdid-in-2016/?utm_term=.eb8c7b44ca7c

Edsall, T. (2017, October 5). How immigration foiled Hillary. The New York Times, Retrieved from https://www.nytimes. com/2017/10/05/opinion/clinton-trump-immigration.html

Newman, B. (2013, April). Acculturating contexts and Anglo opposition to immigration in the United States. American Journal of Political Science, 57(2), 374-390.

PBS. (2017, February 17). The latest election results from the Associated Press. Retrieved from http://www.pbs.org/ newshour/features/2016-election-results/

Pew Research Center. (2017, October 5). The partisan divide on political values grows even wider.

Pew Research Center. (2017, June 22). America's complex relationship with guns.

Pew Research Center. (2016, September 13). The parties on the eve of the 2016 election: two coalitions, moving further apart.

Pew Research Center. (2015, April 7). A deep dive into party affiliation.

U.S. Census Bureau. (2015, February 9). Census divisions and census regions. Retrieved from https://www.census.gov/geo/ reference/gtc/gtc_census_divreg.html

U.S. Census Bureau. (2011, September). The white population: 2010.

Wasserman, D. (2017, March 8). Purple America has all but disappeared. Retrieved from https://fivethirtyeight.com/ features/purple-america-has-all-but-disappeared/ 